\section{COASTAL OCEANOGRAPHIC RESEARCH: TOWARD A GLOBAL UNDERSTANDING}

$\mathrm{T}$ HE 1990S HAVE TURNED into a decade of intense oceanographic research in the coastal area of the world ocean, that region extending from shorelines and estuaries to the continental rise. Despite sound scientific reasons for developing a cosmopolitan understanding of processes operating in the coastal ocean, many of the research programs recently developed or presently being developed have a parochial character.

The situation in the United States seems typical of other developed nations. Dozens of workshops have been held during the past five years with the objective of defining coastal research programs. These workshops usually start with overviews of our state of knowledge regarding fundamental processes in the coastal ocean. However, the research-formulation portions of the workshops quickly evolve into limited discussions of the east coast, the west coast, the gulf coast, and the Alaskan coast.

The reasons for such an evolution are diverse. Mission-oriented funding agencies must focus on their mandated region. In other cases, the fundamental processes of interest can be addressed well for study areas within US boundaries. These explanations make sense. Often however, other explanations are given: distant locations are irrelevant to the US, logistics are too expensive, ship clearances are impossible, et cetera.

Although laboratory experiments and computer models have made significant headway in oceanographic research, ours remains primarily an empirical science. To understand the ocean. we must study the ocean. As one example, the tropics represent a large area of the Earth, receive much dissolved and particulate material, and are characterized by distinct and energetic coastal processes that control material transfer to the world ocean. However, the developed nations are largely nontropical, and research exclusively in their backyards will limit our understanding of tropical and other important coastal processes.

"Blue-water" oceanographic research is routinely undertaken in all oceans including the difficult and remote Arctic and Southern Oceans. Most coastal research is logistically easier, because ports are accessible. With few exceptions, coastal nations would be glad to host an international study, assuming the project was structured properlyfully open and nonintrusive research, real inclusion of local scientists, and educational opportunities for local students.

Certainly a large fraction of coastal research (especially applied research) will continue to examine the coasts of the nations supporting that research. However, much coastal work will be undertaken in the next decades. and some funding agencies have the mandate to extend the frontiers of fundamental knowledge. These agencies should guarantee coastal research that balances local environmental studies and fundamental scientific investigations, even if this leads to research in distant and international locations. Whether as small programs with a few cooperative investigators or large programs with dozens of investigators, interaction among international scientists will help explain coastal systems that extend across political boundaries and that represent the best locales to study unique combinations of operative processes.

International, global programs are underway in the open ocean, in particular, WOCE (World Ocean Circulation Experiment) and JGOFS (Joint Global Ocean Flux Study). On several fronts, international coastal programs are taking tentative steps forward. These programs should be supported, and encouraged to consider the full breadth of coastal settings. Such research is necessary to provide a global understanding of coastal oceanography.

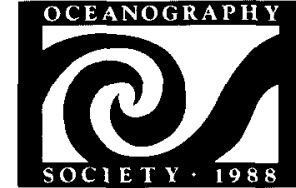

THE OCEANOGRAPHY SOCIETY

1124 Wivenhoe Way Virgınia Beach, VA 23454 USA (804) 496-8958; fax: (804) 496-8960 omnet: OCEANOGRAPHY.SOCIETY

OFFICERS

Arnold L. Gordon, President Margaret Leinen, President-Elect Melbourne G. Briscoe, Secretary

William M. Dunstan, Treasurer

COUNSELORS Larry $P$. Atkinson Richard T. Barber

Stephen E. Calvert

Tommy D. Dickey

Richard Jahnke

Kevin D. Leaman

Charles A. Nittrouer, ex officio

EXECUTIVE DIRECTOR Judi Rhodes

CORPORATE/INSTITUTIONAL SPONSORS Aanderaa Instruments, Inc., Woburn, MA, USA

Chishitsu Chosa-Jo, Ibaraki, Japan

GE Astro Space Division, Princeton, NJ, USA

John G. Shedd Aquarium, Chicago, IL, USA

Monterey Bay Aquarium Research Institute,

Pacific Grove, CA, USA

National Marine Fisheries Service, Silver Spring, MD, USA

Ober, Kaler, Grimes \& Shriver,

Washington, DC, USA

RD Instruments, San Diego, CA, USA

Scripps Institution of Oceanography, La Jolla, CA, USA

Woods Hole Oceanographic Institution, Woods Hole, MA, USA

\section{OceanogRaPHY}

EDITOR

Charles A. Nittrouer

Marine Sciences Research Center

State University of New York

Stony Brook, New York 11794 USA

(516) 632-8651; C.NITTROUER

Telefax: (516) 632-8820

ASSOCIATE EDITORS

James W. Ammerman

Department of Oceanography

Texas A\&M University

College Station, TX 77843 USA

(409) 845-5105; J.AMMERMAN

Gregory J. Brunskill

Australian Institute of Marine Science

PMB No. 3, Townsville, M.C.

Queensland 4810, Australia

(77)789211; G.BRUNSKILL

Ellen R.M. Druffel

Woods Hole Oceanographic Institution

Woods Hole, MA 02543 USA

(508) 257-2000; E.DRUFFEL

Donald B. Olson

RSMAS

University of Miami

Miami, FL 33149 USA

(305) 361-4074; D.OLSON.RSMAS 